\title{
Increased DNA strand breaks in mononuclear cells from patients with rheumatoid arthritis
}

\author{
L L Bhusate, K E Herbert, D L Scott, D Perrett
}

\begin{abstract}
Immune dysfunction is linked with lymphocyte DNA metabolism. In particular, DNA damage may impair lymphocyte function and induce increased cell turnover; such changes are of relevance to the pathogenesis of rheumatoid arthritis. The rate of DNA unwinding in alkaline solution was used as a measure of the number of DNA strand breaks in mononuclear cells freshly isolated from peripheral blood. The rate of DNA unwinding was significantly increased in cells from patients with rheumatoid arthritis compared with those from healthy subjects and from patients with other autoimmune and connective tissue diseases. These findings support the hypothesis that DNA damage is increased in patients with rheumatoid arthritis and it is one factor contributing to immune dysfunction in this disease.
\end{abstract}

Immune dysfunction is a characteristic of rheumatoid arthritis (RA). The immunological changes include autoimmunity, lymphocytic infiltration of the synovium, diffuse lymphadenopathy, and raised immunoglobulin levels. ${ }^{1}$ Decreased responses of both $\mathrm{T}$ and $\mathrm{B}$ lymphocytes to mitogens ${ }^{2}$ and incomplete progression towards lymphocyte activation ${ }^{3}$ have also been described. In addition, patients with RA have an increased risk of sepsis and death due to infection. ${ }^{4}$ Some of these observations could be explained by metabolic changes in lymphocytes.

DNA damage, including strand breaks, invariably occurs in nucleated cells but is usually repaired. For lymphocytes in particular, DNA metabolism is fundamental to proliferation and hence immune function. Evidence for this comes from studies of lymphocyte depletion in patients with severe combined immunodeficiency, associated with the deficiency of adenosine deaminase (adenosine aminohydrolase, E.C. 3.5.4.4) or purine nucleoside phosphorylase (E.C. 2.4.2.1). ${ }^{5}$ In an in vitro model of adenosine deaminase deficiency, the incubation of isolated lymphocytes with deoxycoformycin, an inhibitor of adenosine deaminase, causes deoxyadenosine triphosphate accumulation and results in DNA strand scission. Following excessive DNA strand breaks, nicotinamide adenine dinucleotide (NAD) and adenosine triphosphate (ATP) levels are decreased to such an extent that cell death results - a process termed 'programmed cell death'. A related mechanism (apoptosis) has been described where the activation of endogenous endonuclease accounts for the deletion of selected unwanted lymphocytes. ${ }^{6}$ Additional evidence of the importance of DNA metabolism to lymphocyte function is that their activation in vitro results in the rapid repair of DNA strand breaks. $^{7}$

We suggest that sublethal damage to lymphocyte DNA could account for immune incompetence in patients with RA. We therefore suggest that DNA damage is increased in the lymphocytes of patients with RA. To study this we have investigated one form of DNA damage by measuring strand breaks in peripheral blood mononuclear cells from patients with RA.

\section{Patients and methods}

Blood samples $(10 \mathrm{ml})$ were collected in lithium heparin tubes from the antecubital vein of 15 patients with RA (median age 60, range 50-75, seven women and eight men), 15 patients with osteoarthritis (median age 63, range 45-82, eight women and seven men), and also from six patients with systemic lupus erythematosus (SLE) (median age 41, range 18-60, five women and one man) attending the rheumatology clinic at St Bartholomew's Hospital. Blood was also obtained from five patients (median age 64, range 55-73, two women and three men) with Crohn's disease attending the gastroenterology clinic at St Bartholomew's Hospital. Fifteen healthy donors without evidence of any arthritic disorders (median age 68, range 24-81, six women and nine men) provided control samples.

DNA strand breaks in circulating mononuclear cells were determined using a fluorimetric method for measuring the rate of DNA unwinding, ${ }^{8}$ modified from the procedure of Birnboim and Jevcak. ${ }^{9}$ All steps were carried out under ordinary light. Fresh mononuclear cells were isolated using density centrifugation on Histopaque-1077 (Sigma, Poole, UK). Mononuclear cells were counted and suspended in an isotonic solution (0.25 M mesoinositol, 10 $\mathrm{mM}$ sodium phosphate, $1 \mathrm{mM}$ magnesium chloride, $\mathrm{pH} 7 \cdot 2$ ) to give a cell concentration of $2 \times 10^{6} / \mathrm{ml}$, (typically $8-12 \mathrm{ml}$ ). The suspension was mixed with an equal volume of lysis buffer (9 M urea, $10 \mathrm{mM}$ sodium hydroxide solution, $2.5 \mathrm{mM}$ cyclohexanediaminetetraacetate, $0.1 \%$ $(w / v)$ sodium dodecyl sulphate) and incubated at $0^{\circ} \mathrm{C}$ for $10 \mathrm{~min}$. Aliquots $(0.4 \mathrm{ml})$ of this suspension were placed in eight disposable plastic tubes $(40 \times 9 \mathrm{~mm}$ inner diameter), four 
designated total fluorescence and four partial fluorescence. For the background determination the suspension $(1.6 \mathrm{ml})$ was undivided.

A $0.1 \mathrm{ml}$ aliquot of alkaline solution 1 (AS1; $45 \% \mathrm{v} / \mathrm{v}$ lysis buffer in $0.2 \mathrm{M}$ sodium hydroxide) and $0.1 \mathrm{ml}$ of alkaline solution $2(\mathrm{AS} 2 ; 40 \% \mathrm{v} / \mathrm{v}$ lysis buffer in $0.2 \mathrm{M}$ sodium hydroxide) were very gently layered over the cell suspension in the partial fluorescence tubes using a microsyringe. Aliquots of $0.4 \mathrm{ml} \mathrm{AS1}$ and $0.4 \mathrm{ml} \mathrm{AS2}$ were added to the background fluorescence tube, which was then sonicated for $1-2 \mathrm{~s}$ to denature the DNA and aliquots $(0.6 \mathrm{ml})$ were then distributed to four disposable plastic tubes. The total fluorescence tubes differed from the partial fluorescence tubes only in that the neutralising solution (1 M glucose, $14 \mathrm{mM}$ mercaptoethanol in distilled water) was added before the alkaline solutions AS1 and AS2 so that the DNA was never exposed to a denaturing $\mathrm{pH}$.

All tubes were incubated at room temperature for up to $60 \mathrm{~min}$. Unwinding was terminated at $0,20,40$, and $60 \mathrm{~min}$ by cooling to $0^{\circ} \mathrm{C}$ and the addition of $0.4 \mathrm{ml}$ of neutralising solution to the background and partial fluorescence tubes with mixing. The lysates were homogenised by brief sonication and diluted with $1.5 \mathrm{ml}$ of ethidium bromide solution $(6 \cdot 7 \mu \mathrm{g} / \mathrm{ml}$ ethidium bromide, $13.3 \mathrm{mM}$ sodium hydroxide solution in distilled water), and their fluorescence was measured in an Aminco spectrofluorimeter (model 4-7439) equipped with a mercury lamp (excitation 360 $\mathrm{nm}$ and emission $>520 \mathrm{~nm}$ ). Ethidium bromide binds preferentially to double stranded DNA with an increase in fluorescence. The rate of DNA unwinding (arbitrary units/min) was calculated from the percentage of DNA remaining as double strands after a timed incubation.

In vitro DNA repair was investigated in mononuclear cells from patients with RA and control subjects. Blood samples $(20 \mathrm{ml})$ were collected into lithium heparin tubes from five patients with RA (median age 56, range 42-65, four women and one man) and from five healthy controls (median age 30, range $25-40$, one woman and four men). A $10 \mathrm{ml}$ aliquot of blood was used immediately to measure the rate of DNA unwinding using the procedure described above. A further $10 \mathrm{ml}$ was incubated at room temperature for four hours before the determination of the rate of DNA unwinding.

Statistical analyses were performed using the Mann Whitney-U test using the Oxstat V software package (Oxford Logic, Oxford, United Kingdom).

\section{Results}

Mononuclear cells from patients with RA showed an increased rate of DNA unwinding compared with control subjects. Figure 1 contrasts typical DNA unwinding curves from a patient with RA and from a healthy control subject and shows an increased rate for the patient with RA. Figure 2 shows that the rate of DNA unwinding in the group of 15 patients with RA was significantly increased (median 0.69 , range $0.58-1.02$ ) compared with the 15 controls (median 0.46 , range $0.34-0.52$ ) using the Mann Whitney U test $(\mathrm{p}<0.0001)$. The results for the patients with RA were also significantly different $(p<0.01)$ from the other patient groups studied. There were no differences in the rate compared with controls for patients with osteoarthritis (median 0.50 , range $0.31-0.72$ ) and Crohn's disease (median $0 \cdot 42$, range $0 \cdot 40-0 \cdot 43$ ) (fig 2 ). However, the rate of DNA unwinding for patients with SLE (mean 0.50, range $0.49-0.64$ ) was significantly different $(p<0.01)$ from controls and patients with RA.

The difference between patients with RA and control subjects could not be explained by the variability of the method. The rate of DNA unwinding in mononuclear cells from four healthy volunteers measured on four or five separate occasions over an 18 month period was

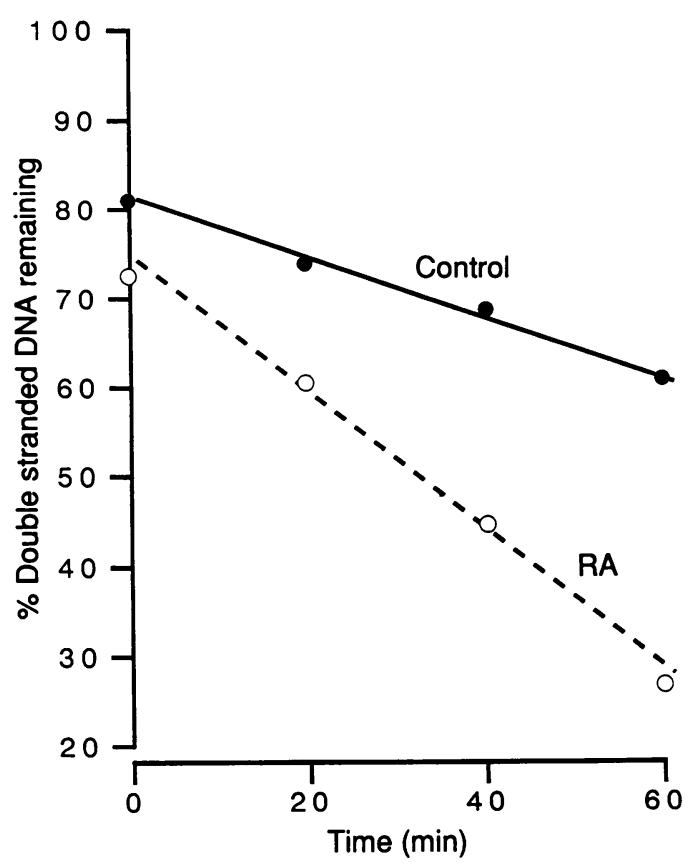

Figure 1 Time course of DNA unwinding for one patient with $R A$ and one control subject. Data expressed as means of triplicate determinations for each time point.

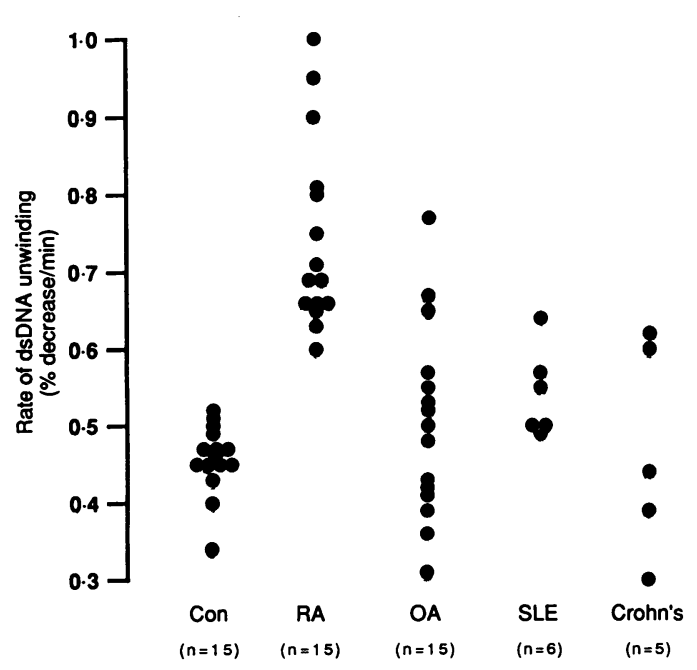

Figure 2 Comparison of the rate of DNA unwinding in different patient groups. Data determined from gradient of unwinding curve such as in fig 1 . (Con) Healthy control subjects; $(R A)$ patients with rheumatoid arthritis; $(O A)$ patients with osteoarthritis; (SLE) patients with systemic patients with osteoarthritis; (SLE) patients with systemic
lupus erythematosus; (Crohn's) patients with Crohn's disease. 


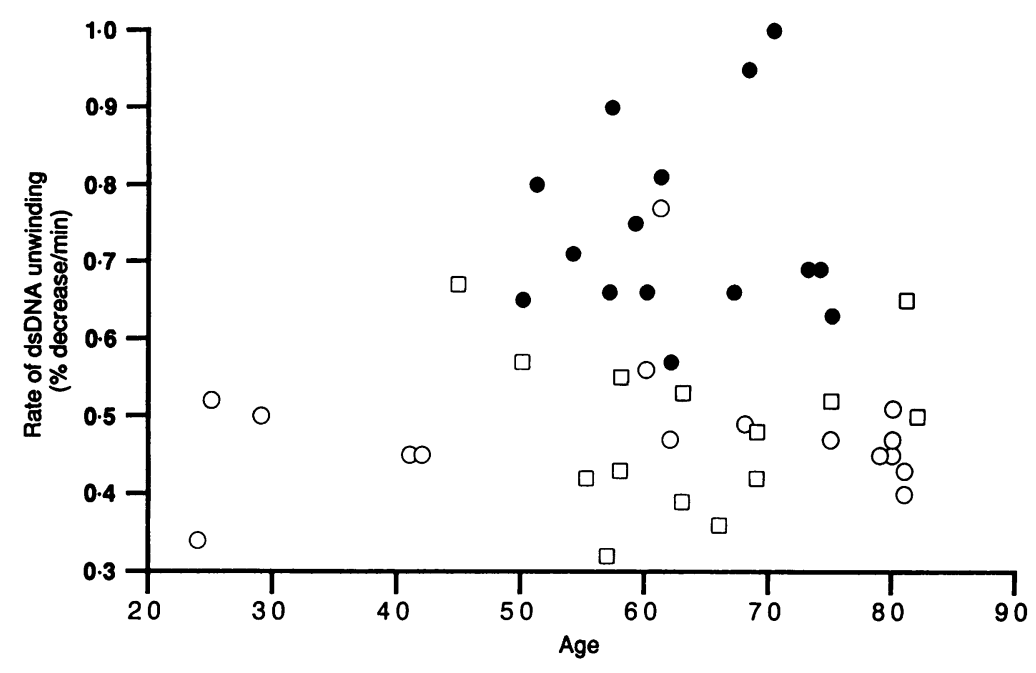

Figure 3 Variation of the rate of DNA unwinding with age of subject. (O) Healthy

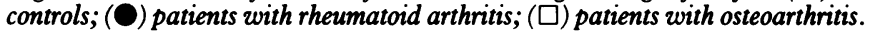

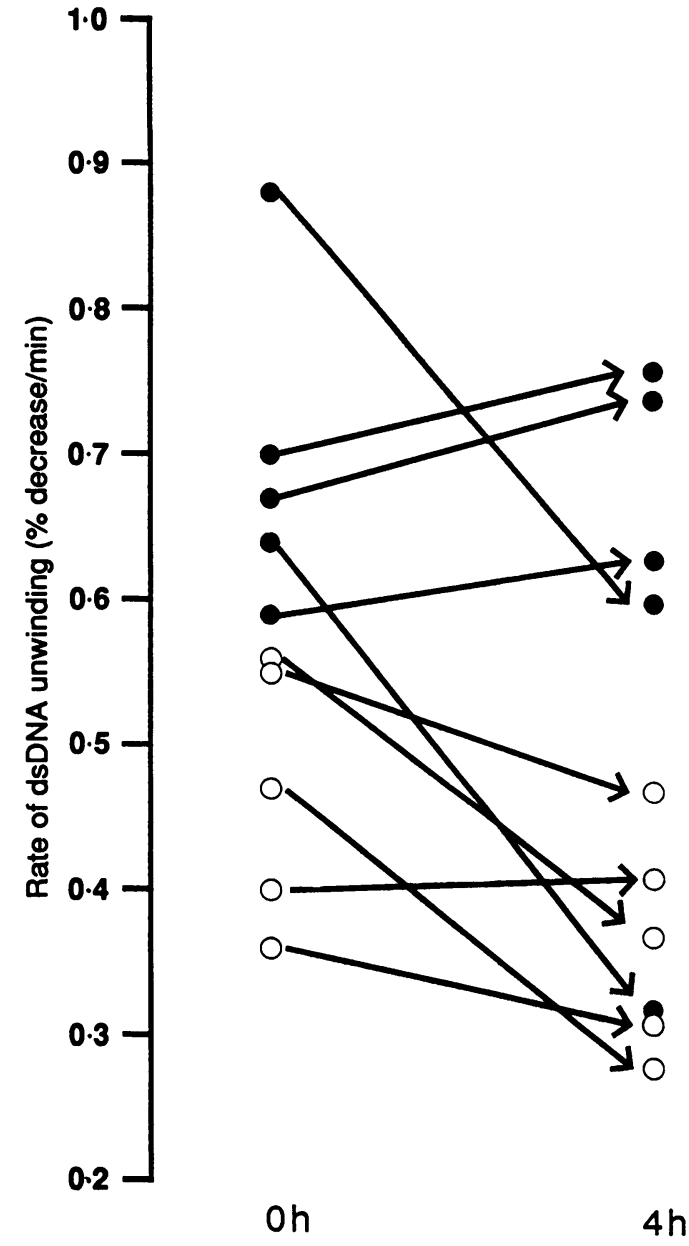

Figure 5 Change in the rate of DNA unwinding following incubation of whole blood at $37^{\circ} \mathrm{C}$. (O) Healthy controls; (O) patients with rheumatoid arthritis; $(0 h)$ Time zero; $(4 h)$ four hours incubation.

constant with an intra-individual coefficient of variation of $3-7 \%$.

There was no evidence that age or sex differences were responsible for the observed increase in the rate of DNA unwinding in patients with RA. Figure 3 shows that the level of DNA unwinding was not related to the age of subject and fig 4 shows that there were no differences in the rates of DNA unwinding between men and women.

Studies on the repair of DNA strand breaks showed some evidence of decreased repair mechanisms in patients with RA. Figure 5 shows that repair occurred in only two of five samples of blood from patients with RA but in four of five control samples as indicated by a decrease in the rate of DNA unwinding in blood incubated for four hours at $37^{\circ} \mathrm{C}$.

\section{Discussion}

DNA can be damaged by many agents such as drugs, radiation, free radicals, and enzymes. ${ }^{10}$ Various forms of chemical damage have been described, including the disruption of phosphodiester bonds producing single and double strand breaks, the formation of DNA-DNA and DNA-protein crosslinks, and base modifications. ${ }^{11}$ DNA is never perfect, as all types of damage can be observed in freshly isolated 
normal cells-however, cells necessarily possess efficient repair mechanisms.

We have investigated DNA integrity in diseased and normal mononuclear cells using an accurate and sensitive DNA unwinding assay. Our results indicate that DNA strand breaks are significantly more common in mononuclear cells from patients with RA than in cells from the other groups studied. This observation was neither sex nor age related. The rate of DNA unwinding was highly discriminatory towards patients with RA (fig 2), but the technical complexity of this particular assay makes it unsuitable for routine use. There was also a lower increase in the rate of DNA unwinding found in our small group of patients with SLE compared with control subjects.

Several explanations could account for our findings, including the presence of more damaging species, drugs, lack of repair, and mononuclear cell type and subset. Firstly, in isolated DNA most generating systems for oxygen free radicals cause DNA strand breaks. ${ }^{12}{ }^{13}$ As there is an increased production of oxygen free radicals in patients with inflammatory diseases, such as RA, ${ }^{14}$ these mechanisms may be of relevance.

The relationship of drugs to our findings is more complex. All patients were receiving a variety of non-steroidal anti-inflammatory drugs and second line agents. Patients with RA and osteoarthritis were receiving approximately the same NSAID regimens, so these are unlikely to be the cause of the DNA damage. However, second line agents have variable effects on the generation of reactive oxygen species. For example, D-penicillamine alone scavenges hydrogen peroxide ${ }^{15}$ but in the presence of copper ions generates hydrogen peroxide ${ }^{16}$; sulphasalazine and its metabolites reduce the generation of reactive oxygen species by neutrophils. ${ }^{17}$

Endogenous nucleases can also damage DNA $^{18}$ by forming internucleosomal breaks. Endonuclease activation can be triggered by a number of stimuli which increase intracellular calcium levels ${ }^{6}$ and can be inhibited by interleukin 1 and 2 . Some studies suggest that in patients with RA there are less interleukin 2 receptors on peripheral blood lymphocytes ${ }^{19}$ and therefore a lack of endonuclease inhibition may be a mechanism causing increased DNA damage.

DNA strand breaks may not reflect the amount of direct DNA damage but may be due in part to excision repair of altered bases. Repair usually involves enzymic cleavage of DNA prior to the removal of damaged bases which would appear as increased numbers of strand breaks. ${ }^{20}$ However, our in vitro observations suggest decreased repair in cells from patients with RA, which could account for the increased rate of DNA unwinding.

Decreased repair of DNA damage has been described in mononuclear cells from patients with autoimmune disease, including RA. ${ }^{21}$ However, these workers used an exogenous methylating carcinogen $(N$-methyl- $N$-nitrosourea) to introduce $\mathrm{O}^{6}$-methylguanine formation. The relevance of such findings to our ex vivo repair studies is unclear, but it is tempting to suggest a generalised defect in DNA repair in patients with RA. Other studies showed that mononuclear cells from patients with autoimmune diseases were more sensitive to inhibition of DNA repair of radiation induced chromosomal damage than controls. ${ }^{22}$ Increased chromosome breaks occur in lymphocytes from patients with RA cultured in vitro in the presence of a mitogen and are thought to be due to a clastogenic factor from blood, probably derived from monocytes. ${ }^{23}$ Furthermore, DNA isolated from lymphocytes of patients with a variety of autoimmune diseases, including RA, was shown to be lower in density than that from healthy controls when analysed by sucrose density centrifugation. This evidence, together with our more quantitative data for damaged DNA in patients with RA, indicates a lack of effective repair of DNA lesions such as strand scission and suggests a mechanism for autoimmune pathogenesis. ${ }^{24}$

Our findings in patients with RA could represent either general cleavage of mononuclear cell DNA or damage to DNA in a particular type or subset of cell. Future studies will aim to measure DNA strand breaks in different mononuclear cell fractions such as monocytes and $T$ and $B$ cells. We were able to obtain a lymphocyte to monocyte ratio for most patients with RA, osteoarthritis and other control subjects (data not shown). No difference between these groups of patients was found, so the increased strand breaks in patients with RA are not correlated with any gross change of mononuclear cell populations.

The biological advantages of DNA strand breaks for lymphocytes are clear: the prevention of mutation caused by excessive DNA damage and deletion of autoreactive lymphocytes. Sufficient DNA strand breaks induced by nucleases or free radical species are therefore required to fulfil these functions but an uncontrolled excess leads to widespread cell death. This scenario closely resembles that described by Dormandy ${ }^{25}$ whereby both an excess and a deficiency of free radicals in vivo could lead to disease. Whatever the cause of the excessive strand scission in cells from patients with RA, the consequences may be immune dysfunction. This would not be as severe as that seen in patients with severe combined immunodeficiency, but represents an impaired immune response. Treatment aimed to control DNA damage and to increase repair should be sought.

We thank the Joint Research Board of St Bartholomew's We thank the Joint Research Board of St Bartholomew's
Hospital, North East Thames Region Health Authority Locally Organised Research Scheme and the Arthritis and Rheumatism Council for financial support. DLS is Muir Hambro Fellow of the Royal College of Physicians.

1 Henderson B, Edwards J C W. The synovial lining in health and disease. London: Chapman and Hall, 1987.

2 Felder M, Doré C J, Knight S C, Ansell B M. In vitro stimulation of lymphocytes from patients with rheumatoid stimulation of lymphocytes from patients with rheumatis. Clin Immunol Immunopathol 1985; 37: 253-61.

3 Pitzalis C, Kingsley G, Lanchbury J S S, Murphy J, Panayi G P. Expression of HLA-DR, DQ and DP antigens and interleukin-2 receptor on synovial fluid $T$ lymphocyte subsets in RA: evidence for 'frustrated' activation. $\mathcal{f}$ Rheumatol 1987; 14: 662-6.

4 Prior P, Symmons D P M, Scott D L, Brown R, Hawkins C $\mathrm{F}$. Cause of death in rheumatoid arthritis. $\mathrm{Br} \mathcal{F}$ Rheumatol 1984; 23: 92-9. 
5 Carson D A, Seto S, Wasson D B, Carrera C J. DNA strand breaks, NAD metabolism, and programmed cell death. Exp Cell Res 1986; 164: 273-81.

6 Wyllie A H. Glucocorticoid induced thymocyte apoptosis is associated with endogenous endonuclease activation. Nature 1980; 284: 555-6.

7 Johnstone A P. Rejoining of DNA strand breaks is an early nuclear event during the stimulation of quiescent lymphocytes. Eur $\mathcal{F}$ Biochem 1984; 140: 401-6.

8 Bhusate L L, Herbert K E, Perrett D. Application of a fluorometric method for measuring DNA strand breaks in purified DNA. Biochem Soc Trans 1989; 18: 676-7.

9 Birnboim H C, Jevcak J J. Fluorometric method for rapid detection of DNA strand breaks in human white blood cells produced by low doses of radiation. Cancer Res 1981; 41: 1889-92.

10 Castellani A. DNA damage and repair. New York: Plenum Press, 1989

11 Dizdaroglu M. Application of capillary gas chromatographymass spectrometry to chemical characterization of radiationinduced base damage to DNA. implications for assessing DNA repair processes. Anal Biochem 1985; 144: 593-603.

12 Bhusate L L, Herbert K E, Perrett D. Measurement of single strand breaks in isolated DNA induced by free radicals. Analytical Proceedings (in press)

13 Aruoma I O, Halliwell B, Dizdaroglu M. Iron ion dependent modification of bases in DNA by the superoxide radicalgenerating system hypoxanthine/xanthine oxidase. $\mathcal{F}$ Biol Chem 1989; 264: 13024-8.

14 Merry P, Winyard P G, Morris C J, Grootveld M, Blake D R. Oxygen free radicals, inflammation, and synovitis: the current status. Ann Rheum Dis 1989; 48: 864-70.

15 Zoschke D C, Kaja J. Suboptimal levels of hydrogen peroxide scavengers in synovial fluid: in vitro augmentation with slow acting antirheumatic drugs. $\mathcal{F}$ Rheumatol 1989; 16: 1233-40.

16 Lipsky P. Immunosuppression by $D$-penicillamine in vitro. Inhibition of human $\mathrm{T}$ lymphocyte proliferation by coppe or ceruloplasmin-dependent generation of hydrogen peroxide and protection by monocytes. $\mathcal{f}$ Clin Invest 1984; 73: 53-65.

17 Miyachi Y, Yoshioka A, Imamura S, Niwa Y. Effect of sulphasalazine and its metabolites on the generation of reactive oxygen species. Gut 1987; 28: 190-5.

18 McConkey D J, Orrenius S, Jondal M. Cellular signalling in programmed cell death (apoptosis). Immunol Today 1990; 11: $120-1$

19 Smith M D, Roberts-Thomson P J. Lymphocyte surface marker expression in rheumatic diseases: evidence for prior activation of lymphocytes in vivo. Ann Rheum Dis 1990; 49: 81-7.

20 Lindahl T. DNA repair enzymes. Ann Rev Biochem 1982; 51: 61-87.

21 Lawley P D, Topper R, Denman A M, Hylton W, Hill I D, Harris G. Increased sensitivity of lymphocytes from patients with systemic autoimmune diseases to DNA alkylation by the methylating carcinogen $N$-methyl- $N$ nitrosourea. Ann Rheum Dis 1988; 47: 445-51.

22 Harris G, Holmes A, Sabovljev S A, et al. Sensitivity to Xirradiation of peripheral blood lymphocytes from ageing donors. Int $\mathcal{F}$ Radiat Biol 1986; 50: 685-94.

23 Emerit I, Levy A Camus J P. Monocyte-derived clastogenic factor in RA. Free Radic Biol Med 1989; 6: 245-50.

24 Harris G, Cramp W A, Edwards J C, et al. Radiosensitivity of peripheral blood lymphocytes in autoimmune disease. Int $\mathcal{f}$ Radiat Biol 1985; 47: 689-99.

25 Dormandy T L. In praise of peroxidation. Lancet 1988; ii: 1126-8. 